\title{
Aqroechology Situation in Projects, Problems and Solving Ways in Qazarians in Azerbaijan
}

\author{
RAE ZH Aliyev* \\ Institute of Soil Science and Agrochemistry of ANAS, Azerbaijan \\ Received: June 15, 2018; Published: June 27, 2018 \\ *Corresponding author: RAE ZH Aliyev, Institute of Soil Science and Agrochemistry of ANAS, baku, Azerbaijan
}

\begin{abstract}
Annotation
Natural and anthropogenic impacts of natural soil, grass cover and mainly pasture (degradation), degradation of desertification and degradation of forest ecosystems have led to a considerable sharp reduction in the feed base for animal husbandry development. For a wellknown purpose in the country of strategic importance, the assessment of existing natural and cultural pasture areas in the country from their agro economic security perspective, using scientifically-based research in the field of approach and the use of effective methods is a problem that is relevant to agrarian science. Here is a summary of Gobustan analyzes the modern agro ecological situation of the pastures, evaluates land and agrochemical grouping and so on. it is emphasized that it is important to carry out comprehensive measures to improve the quality of the area in the affected areas.
\end{abstract}

Abbreviations: PA: Physical Inactivity; TV: Television; FVC: Fruit and Vegetable Consumption; SMK: Cigarette Smoking; SMKL: Smokeless Tobacco; ALC: Alcohol

\section{Introduction}

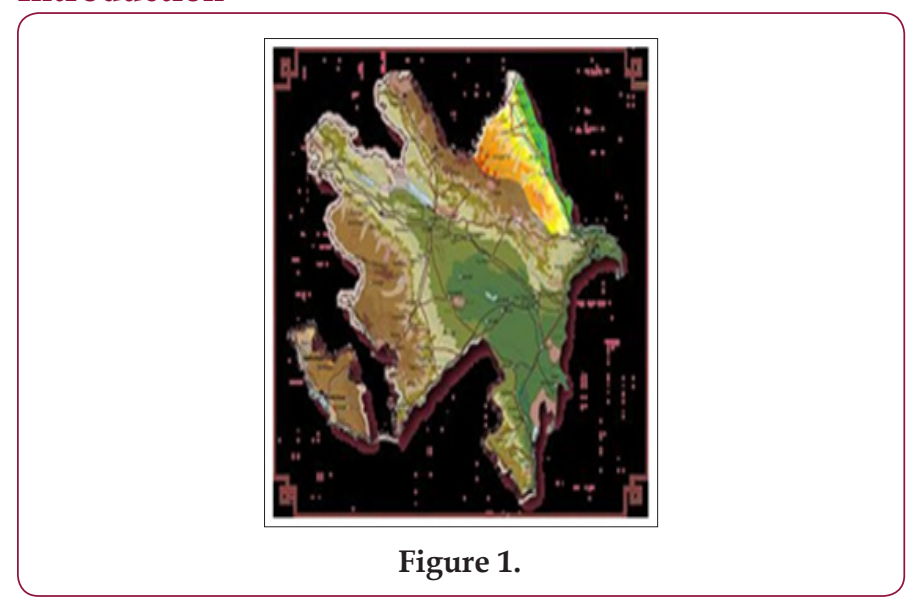

The fact that agriculture has been degraded by important degraded lands in the Republic of Azerbaijan, including the natural pasture and mowing areas, is a consequence of their lack of productivity due to the use of animal breeding for their development purposes. On the other hand, the structure of the oath is low in the high nutritional concentrates causing excessive loading of natural forage areas, erosion and salinization of land as a result of their uncontrolled exploitation, serious damage to the country's forest resources, water resources and the environment as a whole (Fig ure 1). Efficient utilization of land resources, improving fertility, restoration, protection and productivity management are essential for the development of agrarian sector in Azerbaijan and should be carried out on a day-to-day agro ecological basis. In addition to the development of agriculture in the country, the development of livestock and grazing agriculture, which is one of the main directions of agriculture, requires the expansion of the pastureland and pasture areas and increase the production of feed for internal resources.

From this point of view, the object of the research confirms that the severe degradation processes observed in winter grazing in the selected Gobustan district cause the occurrence of less productive land areas to endanger crop rotation. From this point of view, research is being carried out in order to increase productivity through more progressive methods in the country, to improve the protection of summer pastures and mowers, to increase their use and to preserve biodiversity. Reasoning Research The main reason for the unacceptable change in the natural resource potential is pasture plowing, large-scale agromeliorative work, excessive livestock grazing and strong man-caused effects. Thus, the problem of increasing the number of livestock is the irreversible stages of overgrazing as pasture degradation. Herbaceous degradation leads to a reduction in biodiversity, fragmentation of the biosphere structure and the inability of the ecosystem to control and regenerate itself. The creation of a solid feed base, which is the basis for the improve- 
ment of our pasture ecosystems, which is the main habitats for the flora and fauna of the region, as well as the basis of the capacities of the country's economy, is a part of the well-known State Program. Along with these, the research merit is a problem of relevance to the needs of the day in the current market economy and expects its own scientifically-researched research with researches.

\section{Object of Research}

The main purpose of the research was to expand the pastures and grazing areas through the application of the results, using the latest research methods in the complex approach of agro ecological features of the country's winter pastures in Gobustan region.

\section{Object and Methodology}

The object of research was winter pastures located in the territory of Qobustan, their main soil and vegetation. The soil erosion surveys carried out with the practice of suburban soils, monitoring of dangerous gray-brown soils of widespread erosion in the site of the research object were analyzed and the agro ecological assessment was carried out on the basis of commonly accepted methodology of academician Q.Sh. Mammadov [1] (Table 1). Analyzes have been made of [2-4] methodologies taken from soil and plant samples taken from the field of soil research and field studies for laboratory studies in selected field of practice. The main criterion for assessment of grazing lands was the objective indicators affecting their genetic and agrochemical quality: total humus, nitrogen, phosphorus, potassium, total absorbed bases: $0-20 \mathrm{~cm} ; 0$ to $50 \mathrm{~cm}$; Reserve 0-100 cm. Reserves of selected agrochemical indicators $(\mathrm{t}$ / ha) are generally accepted for land parcels formula calculated on the formula. During the research, the same plot of land, plant, landscape, geobotany maps and archive map fund of ANAS Institute of Soil Science and Agrochemistry were used [5].

Table 1: Information on the erosion of terrain soils in the study area.

\begin{tabular}{|c|c|c|c|c|c|c|c|c|c|c|c|c|}
\hline \multirow{4}{*}{$\begin{array}{c}\text { No. } \\
1\end{array}$} & \multirow{4}{*}{$\begin{array}{c}\text { Districts } \\
2\end{array}$} & \multirow{4}{*}{$\begin{array}{c}\text { Common area } \\
\text { (thousand ha) } \\
3\end{array}$} & \multicolumn{10}{|c|}{ Including extent of erosion process } \\
\hline & & & \multicolumn{2}{|c|}{ Unsuccessful areas } & \multicolumn{2}{|c|}{$\begin{array}{l}\text { Areas exposed to } \\
\text { erosion }\end{array}$} & \multicolumn{6}{|c|}{ From him } \\
\hline & & & \multirow{2}{*}{$\begin{array}{c}\text { ha } \\
4\end{array}$} & \multirow{2}{*}{$\begin{array}{c}\% \\
5\end{array}$} & \multirow{2}{*}{$\begin{array}{c}\text { ha } \\
6\end{array}$} & \multirow{2}{*}{$\begin{array}{c}\% \\
7\end{array}$} & \multicolumn{2}{|c|}{ Weak } & \multicolumn{2}{|c|}{ Medium } & \multicolumn{2}{|c|}{ Violence } \\
\hline & & & & & & & 8 & 9 & 10 & 11 & 12 & 13 \\
\hline 1 & Gobustan & 153,1 & 43,5 & 23,5 & 143,7 & 76,5 & 24,4 & 3,0 & 33,5 & 17,9 & 85,8 & 45,9 \\
\hline 2 & Shamakhi & 161,2 & 62,8 & 39,8 & 94,8 & 60,2 & 38,3 & 23,3 & 21,6 & 13,7 & 34,9 & 22,2 \\
\hline 3 & Ismailli & 194,4 & 89,8 & 41,3 & 127,5 & 58,7 & 55,8 & 25,7 & 28,3 & 13,0 & 43,4 & 20,0 \\
\hline 4 & Aghsu & 108,4 & 82,8 & 77,9 & 39,1 & 32,1 & 13,8 & 11,3 & 8,5 & 7,0 & 16,8 & 13,8 \\
\hline
\end{tabular}

\section{Research Progress and Analysis of Results}

It was noted that the total area of the land area of the cadastral region is 601.0 hectares and covers the flat and foothills of the district. The main types of landscapes are semi-desert and medium-sized dry steppes. Depending on the degree of moisture (Md$0.10-0.15)$, the terrain belongs to the zonal zone. The average annual precipitation is $250-450 \mathrm{~mm}$. The district is completely heated. The total of temperatures above 100 is $4700-38000$. The winter is soft here. The length of the vegetation period is 226-211 days. Mainly gray-brown (brown), light gray-brown (chestnut), common gray-brown (chestnut), grass-gray, gray, light gray, primrose, grassgrass, forest grass, wet grass soils have spread. Grass-brown, grassgray and gray soil types are widely used in agriculture. However, in the pastures, the soils of these lands are widespread and saline, clay, and heavy-grained soils.

In general, winter pastures spread over the cadastral plains cover 119.3 thousand hectares, which is distributed in administrative districts as follows: Yevlakh (left bank) - 7,700 hectares; Agdash - 9,5 thousand ha; Goychay - 6.6 thousand ha; Ujar - 19,5 thousand ha; Zardab - 19.5 thousand ha; Kurdemir - 51,0 thousand ha. The distributed lands in these districts were evaluated with the following points [4]: dark-brown-brown-100 points; graybrown-85; light gray-brown-73; dark gray-meadow-90; gray-meadow-71; gray grass-60; grass-boz-88; grass-gray-brown -75; Subasar meadow-67; gray-63; open-gray-54; elementary-boz-54; mead- ow-forest-86; wet grass-58; gray-brown - 57 points. These points are according to the type and semi-type of land on the main bonitet scatter of the land allocated by Academician G.Sh Mammedov. [1] These lands are widely spread in the pasturelands, such as erosion, salinization, slaughtering, aridization, desertification and so on. An open skyscraper was established, taking into account the correlation coefficients on the indicators, so that it was possible to divide the land into qualitative groups. It has been found out that in the main grazing areas of the cadastral region, saline, saline, clay, heavy gilles, soils have been widely spread.

For our part, the soil erosion research conducted by the Institute of Soil Science and Agrochemistry shows that the erosion process is widespread in the area. Here, the erosion loses its structure, increases the amount of carbonates, the amount of absorbed bases decreases, and the mucous membrane goes to the surface, the food is washed away. From the morph ones of the cuttings of the area, it appears that significant changes have occurred in the genetic layer of eroded soils. Here, the volume and specific weight of water-physical properties of eroded soils significantly increased in heavily soaked soils: $1.15 \mathrm{~g} / \mathrm{cm} 3 ; 2,62 \mathrm{~g} / \mathrm{cm} 3$ and porosity 55, 20\%. It was found out in the study that in the average degree of soils, 1, 09 $\mathrm{g} / \mathrm{cm} 3,2.57 \mathrm{~g} / \mathrm{cm} 3$; the porosity was $53.45 \%$. It has been noted that the humus, the total nitrogen content of the erosioned soil has dropped significantly in the heavily soaked soils: $1,50 \%$ humus; $0,084 \%$ of total nitrogen. On average, this figure is $4,29 \%$; $0.225 \%$. 
The mechanical composition of these lands we are researching is clay soils: the amount of physical clay has been $75.20 \%-63.60 \%$. Because of the erosion process, the erosion process has become much worse in the structural and aggregate composition of soils. In the heavily soiled soils, the size of $1 \mathrm{~mm}$ large aggregates is $52.68 \%$, and water-resistant aggregates are $21.20 \%$; these figures are $60.85 \%$ in moderately soiled soils; $33.80 \%$. The ability to absorb gray-brown soils has also declined as a result of the erosion process. The amount of bases absorbed here has reached $17.5 \mathrm{mg}$ / sq. / $13.0 \mathrm{mg} /$ eq, and $37.0 \mathrm{mg} /$ eqw-26 mg / eV in moderate wash. It should be noted that in these eroded soils, the quantity of mesopharynphous phosphorus has diminished, and the nitrogen forms - water-soluble ammonia, absorbed ammonia, and nitrates have been reduced. From the analysis of our research results, it is concluded that by applying complex agro-meliorative measures, it is possible to increase the productivity of pastures in the reserve.

Thus, various plants (phytomeliorants, clover, rye, raspberries, rye, etc.) have a positive impact on soil fertility, aggregation intensity of nutrients in soil, physical-chemical and agro physical properties of soil. In many respects, it has been proven that the application of the fertilization system under the clover plant (with different norms and proportions) plays an exceptional role in improving soil fertility parameters, water-physical properties and improving the food regimen of the cultivated plant, impacts the effect [5,3].

In accordance with the recommendations of BH Aliyev [5,6], mineral fertilizers are delivered more effectively to the localized root system, not to the whole area, in order to increase the economic efficiency of fertilizers and reduce the negative impact of their application on the environment. This method yields more fruit and viticulture. The author believes that the use of progressive irrigation methods in the current shortage of water is unavoidable for the fertilizers to be combined with irrigation water, which increases the productivity of the nutritional components of the plant, increases productivity, improves its water-physical properties and improves soil fertility, which is, in its turn, one of the most crucial methods of struggle for the development of the erosion process, and is a broad-based application as an immediate measure. From these recommendations, it can be concluded that the cadastral region can be substantially improved by means of surface improvement aimed at the prevention of winter pastures soils erosion.

\section{Results}

a) The $40 \%$ of our researchers are eroded, salty, and salty. it is necessary to use perennial herbs to improve the fertility of these clay and heavy-clay soils. It is possible to improve the soil fertility by giving it mineral fertilizers under the grass, taking clover sage and mixed sowing.

b) Leguminous herbs are indispensable in the fight against erosion. This grazing soil enriches with organic residues, and their root extend to the surface by absorbing calcium from the lower layers of the soil, improve soil structure, improve water resistance, enriches soil erosion elements, and improves soil fertility.

c) Through the use of erosion control measures, the complex surface improvement in winter pasturelands will allow for the recovery and expansion of natural pastureland, resulting in the availability of cheap and high-quality feed, which is essential for the development of livestock breeding in the country, is achieved.

\section{Summary}

The results of the research prove that degradation and desertification of winter pastures in Upper Shirvan region caused a sharp deterioration in the feed base of livestock. With this, targeted research is an urgent task. The article presents an analysis of the current state of the soil cover, and its importance in terms of its susceptibility to erosion and development. As a result of the research, it is recommended to develop and implement complex agrochemical, agro technical and agro-meliorative measures to improve them.

\section{References}

1. KG Sh Mammadov (1987) Methodological indications on the semiotic cultivation of cereals. Pp. 197.

2. BH Aliev, Aliev ZH (2003) Irrigated agriculture in the mountain and foothill regions of Azerbaijan. Monograph Publishing house "Nurlan Zia EPG Ltd" Baku, pp. 330.

3. Aliev ZH (1999) The premises of the decision of the problems moisture provides agriculture cultures production in mountain and foothill region Azerbaijan. The works SRI "Erosions and Irrigations" Baku, pp.125-129.

4. BŞ Şakuri (2008) Influence of mineral and microorganisms on biological processes in gray-brown mountain-brown and carbonate mountaingray-brown (chestnut) soils of the Greater Caucasus. Land and water resources protection, Baku.

5. Aliev ZH (2007) The premises about the most important problem of the agriculture in provision water resource mountain and foothill regions Azerbaijan, J AAS, pp.179-182.

6. BH Aliev, Aliev ZH (2001) Zoning of territory of Azerbaijan Republic on choosing advanced irrigation techniques. Monograph Publishing house "Ziya”, Baku, pp. 297.

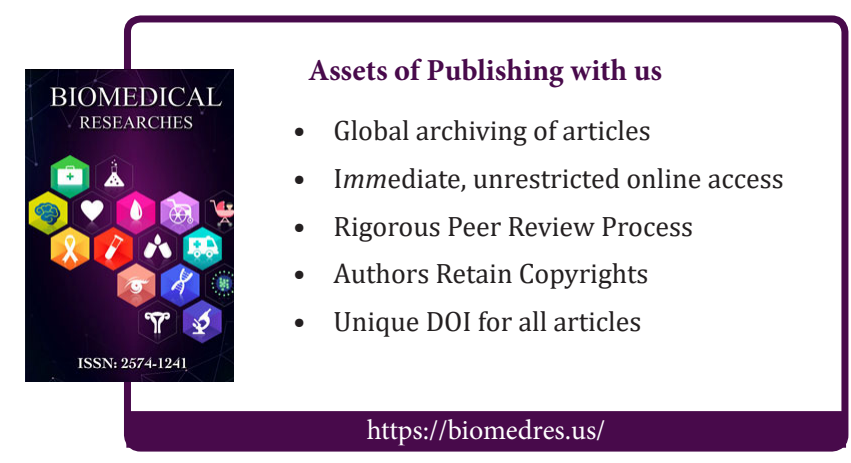

